\title{
Wave Climate of the Coastal Zone of the Crimean Peninsula
}

\author{
B. V. Divinsky*, R. D. Kosyan
}

Shirshov Institute of Oceanology, Russian Academy of Sciences, Moscow, Russian Federation

*e-mail: divin@ocean.ru

The main goal of the present paper is to assess climatic features of the wind wave and swell distribution in the coastal zone of the Crimean Peninsula. Method of research is the mathematical modeling. The modern spectral wave model DHI MIKE $21 \mathrm{SW}$ is used. The model was preliminary calibrated for the purpose of correct dividing the mixed surface waves into the components corresponding to pure wind waves and swell. The basic calibration parameters are the coefficients conditioning numerical interpretation of the energy dissipation processes resulting from white-capping (wave breaks in deep water). The research has resulted in creating a database of integral parameters of the wind waves and swell in the Black Sea for 1979-2016 with the 1-hour time resolution. The features of spatial distribution of the wind wave and swell powers, and also some statistical characteristics of wave variability are analyzed for the sea areas adjacent to the Crimean coast. It is shown that the swell contribution to the total wave energy of the surface waves increases from the western coast of the Crimea Peninsula towards the eastern one. Nearby the western coast, the swell contribution (in the average annual balance) constitutes about $15 \%$, whereas nearby the southeastern one it exceeds $30 \%$.

Keywords: mathematical modeling, DHI MIKE 21 SW model, wind waves, swell, climate.

Acknowledgements. Statement of the task was carried out within the framework of the program 0149-2018-0013, the experimental data analysis - owing to the RSF financial support (Project No. 14-17-00547), mathematical simulation and computational part - with the support of RFBR grants (Projects No. 16-45-230781 and No. 17-05-00183).

For citation: Divinsky, B.V.and Kosyan, R.D., 2018. Wave Climate of the Coastal Zone of the Crimean Peninsula. Physical Oceanography, [e-journal] 25(2), pp. 93-101. doi: 10.22449/1573-160X2018-2-93-101

DOI: $10.22449 / 1573-160 \mathrm{X}-2018-2-93-101$

(C) 2018, B. V. Divinsky, R. D. Kosyan

(C) 2018, Physical Oceanography

Introduction. Generally, there are two main components in the structure of surface waves: pure wind waves (WW) and swell. The development of wind waves is directly related to the local wind field. Swell include waves propagating outside the generation zones or the zones with phase velocity exceeding wind speed (e.g. [1]). In the open ocean, swell can propagate to hundreds and thousands of kilometers. In the Black Sea, the characteristics of the swell are limited by the constrained geographic dimensions and sea area closeness.

The usual practice is representation of the wave field features in the form of a set of integral parameters (significant wave height, average period, general direction of the propagation). Such an approach is justified under conditions of a homogeneous wave field. If the wave spectrum is formed as the result of the interaction of several wave systems, it seems quite natural to obtain separate wave statistics for each of them.

In addition to purely research interest, the wave field separation into individual components allows the following: more correct description of the spatiotemporal structure of surface waves; more effective calculation of wave loads on structures in the coastal zone, as well as dangerous phenomena in protected water areas (lowPHYSICAL OCEANOGRAPHY VOL. 25 NO. 22018 
frequency oscillations); clarification of the schemes of redistribution and transport of bottom sediments; correct predictive estimates of the wave situation in the interests of maritime navigation.

Currently, information on the characteristics of mixed waves and swell is provided within the framework of some global reanalysis projects, for example, the European Center for Medium-Range Weather Forecasts (ECMWF) [2]. The results of recent studies carried out based on such arrays made it possible to assess the climatic features of the swell wave distribution of on the ocean scale [3-6]. The use of ready-made swell parameters from the reanalysis database does not appear to be correct for the Black Sea, since the time interval for such data is 3 hours. In particular, a set of wave statistics characterizing the storm activity in the Black Sea was studied in [7]. It was shown that the average duration of the storm is 1425 hours, depending on the established threshold level. Therethrough, the 3-hour discreteness of the output fields of wind waves is clearly inadequate for the synoptic conditions of the Black Sea.

There are few scientific publications devoted to the separate description of the components of surface waves in the Black Sea water area. In [7] an attempt to construct climatic spectra for individual wave classes for the northeastern sea part was made. The analysis was based on experimental data [8]. The repeatability of climatic spectra for pure wind waves, swell and mixed waves is 43,32 and $25 \%$, respectively. In [9], the characteristics of wind-induced waves and swell were analyzed according to ECMWF reanalysis data in the southern Black Sea for 01.10.2000-28.02.2006 with an interval of 12 hours. For synoptic conditions of the Black Sea, this discreteness is clearly inadequate and the results obtained can be regarded as highly estimated. One of the recent works is the study [10], in which the authors used the capabilities of the SWAN model updated version for automatic separation of wave components. The result of the work was the climatic fields of wind-induced waves and swell for the Black Sea basin for 4 seasons. Unfortunately, the issues related with the model calibration and the quality of the separation were not considered in this work. Setting parameters of the model, especially the coefficients determining the wave energy dissipation in deep water are critically important when separating from the general mixed wave the components corresponding to wind waves and swell. Different values of parameters entail different results. In the present paper, a preliminary calibration of the wave model is carried out using the experimental two-dimensional spectra of real mixed waves.

Separation of Wave Component. Now, the attention should be turned on description of the model used, the experimental data and also the physical aspects of modeling. An important detail should be also noted. Absolutely clear experimental wave field separation into individual components is a rather rare phenomenon. Mixed waves are most often monitored. They are formed under the effect of many external and internal factors. A single-valued interpretation of the resulting frequency-directed spectrum in such situations is hardly possible, so an element of subjectivity is inevitable in the conclusions.

DHI MIKE 21 SW Spectral Wave Model of the Danish Hydraulic Institute [11] is applied in the preset study. The detailed description of the model and its verification are given in [12]. Below the main issues are listed: 
- the model realizes the basic physical mechanisms of birth, transformation and attenuation of wind-induced wave;

- the uneven computational grid covers the whole water area of the Black and Azov Seas and consists of 20,000 computational elements;

- the ERA-Interim global atmospheric reanalysis data submitted by the European Center for Medium-Range Forecasts (http://apps.ecmwf.int) are used as the initial wind fields. The region under consideration is bounded by the $40-47^{\circ} \mathrm{N}$., $27-$ $42^{\circ} \mathrm{E}$ coordinates. The spatial resolution of the wind fields is the same in latitude and longitude and is $0.25^{\circ}$, the time step is 3 hours.

During the model verification, experimental data obtained by various devices (Datawell buoy stations, $A D C P$, string waveriders), as well as by the satellite observations was used. For the separation of surface waves into components, the initial experimental data for frequency-directed spectra construction is necessary. At the disposal of the authors, there are initial materials of the wave experiment in the area of Gelendzhik, conducted in 1998-2003 using the Datawell Waverider [8]. The installation point coordinates are $44^{\circ} 30^{\prime} 40^{\prime \prime} \mathrm{N}, 37^{\circ} 58^{\prime} 70^{\prime \prime} \mathrm{E}$; the depth of the place is $85 \mathrm{~m}$.

The two-dimensional spectrum of surface waves provides an opportunity to study the wave energy distribution features in both the frequency domain and in the propagation directions, thereby separating the individual wave systems.

Several issues are noted below: in the analysis, the determining one is the position of the local peaks of the two-dimensional spectral density relative to the prevailing wind direction; in the case of a change in atmospheric conditions over the sea area, the frequency-directed spectrum may contain (in addition to the wind wave component) several swell systems. Generally, these are two swell systems: primary - with respect to the current wind wave and the secondary one. The energy parameters of the secondary swell are much weaker than the primary one. For this reason, the task of explicit detailing is not set and the concept of "swell" means the surface excitement, the direction of propagation of which does not agree with the general direction of the wind.

Wave Model Setup. DHI MIKE 21 SW Spectral Wave model allows auto separation of the simulated field of wind-induced waves into separate components. In this case, the quality and physical validity of the separation ultimately depend on the user setups. This model is based on the solution of the wave energy balance equation. The main physical processes (wind pumping, white-capping, energy dissipation due to bottom friction and collapse) are described by semiempirical functions. Assuming that under our conditions the effects associated with bottom friction and the wave breaking in shallow water are of a local nature; so the parameters describing these effects are not involved in the model configuration. The main calibration parameters are the two coefficients, $C_{\text {dis }}$ и $\delta_{\text {dis }}$ determining the numerical interpretation of the energy loss processes due to the white-capping (in other words, the wave breaking in deep water). In this case, the coefficient $C_{\text {dis }}$ determines the overall level of dissipation and affects primarily the wave height; the parameter $\delta_{\text {dis }}$ is an analog of the function weighting and, controlling the dissipation of the spectral components, affects the wave periods. $\delta_{\text {dis }}$ variation within $0-1$ 
allows increasing or decreasing the degree of dissipation at low or high frequencies.

Strictly speaking, both coefficients cannot be interpreted independently of each other: for example, the choice of the coefficient $C_{\mathrm{dis}}$ depends on the set value of $\delta_{\text {dis. }}$ In addition, the optimum setup of $C_{\text {dis }}$ and $\delta_{\text {dis }}$ parameters is largely determined by the physical conditions for the generation and propagation of surface waves $[13,14]$.

In our opinion, the correct setup of the spectral model in the conditions of automatic separation of the simulated field of wind waves into individual components should ensure: the correspondence of the model and experimental integral characteristics, as well as two-dimensional energy spectra for the entire wave field and its components (swell and wind-induced waves); obtaining of the physically grounded statistical estimates of swell and wind wave parameters.

The carried-out numerical experiments made it possible to determine the optimal configuration of the spectral model:

- 50 spectral frequencies are distributed in the 1.6-17.3 s period range using the relations $f_{n}=f_{0} C^{n}\left(f_{0}=0.055 \mathrm{~Hz}, C=1.05, n=1,2 \ldots 50\right)$;

-number of the discrete directions is 32 , that is, the model resolution in the directions is $11.25^{\circ}$;

- values of the coefficients determining the energy dissipation due to the white-capping, are the following: $C_{\mathrm{dis}}=5.5, \delta_{\mathrm{dis}}=0.15$;

- separation of wave components is carried out using a criterion that takes into account the "age" of the waves. At that, the wave component is taken corresponding to swell accomplishing the condition $\frac{U_{10}}{c} \cos \left(\theta-\theta_{w}\right)<0,83$, where $c$ is the phase velocity of waves; $\theta, \theta_{w}$ are the direction of waves and wind, respectively [15].

As an example, the results of an automatic separation of surface wave components for December 1997 are given. As follows from Fig. 1, the spectral model separates the components of the swell and pure wind-induced waves quite confidently. The limited number of experimental calendar dates for which the separation was performed is due to the fact that one of the goals of the proposed study is to demonstrate the DHI MIKE $21 S W$ capabilities for component separation. The existing algorithms for separating the experimental spectra, which is applied to large data sets, were not used in the present study. The reason is that the approaches to identifying spectral peaks (relative heights, distances between them, etc.) realized in these algorithms cannot be universal and require their own verification. A selective analysis of two-dimensional experimental spectra was carried out manually, taking into account the general characteristics of the wind.

Thus, setup of the spectral model adequately separating the wave field into individual components was carried out. The model frequency-directed wave spectra as a whole correspond to two-dimensional experimental spectra. A certain drawback of the model is the reassessment of the contribution to the general excitement of swell components under conditions of a sharp wind change.

An important detail should be noted. The setup parameters used in describing the processes of wave energy dissipation due to white-capping, are obtained as 96 PHYSICAL OCEANOGRAPHY VOL. 25 NO. 22018 
a result of experimental data analysis for the northeastern Black Sea. It is difficult to say how universal they are for the entire sea area. An obstacle to resolving this issue is the poor coverage of the Black Sea by experimental wave stations, which make it possible to obtain the main characteristic of wave motion - the twodimensional energy spectra. In the presence of observational network data, local features (and a significant refinement of the model) can be taken into account by constructing spatial maps of the distribution of necessary parameters.

Taking these restrictions into account, the attempt to estimate the features of the propagation of surface wave components in the Black Sea in the first approximation was carried out.

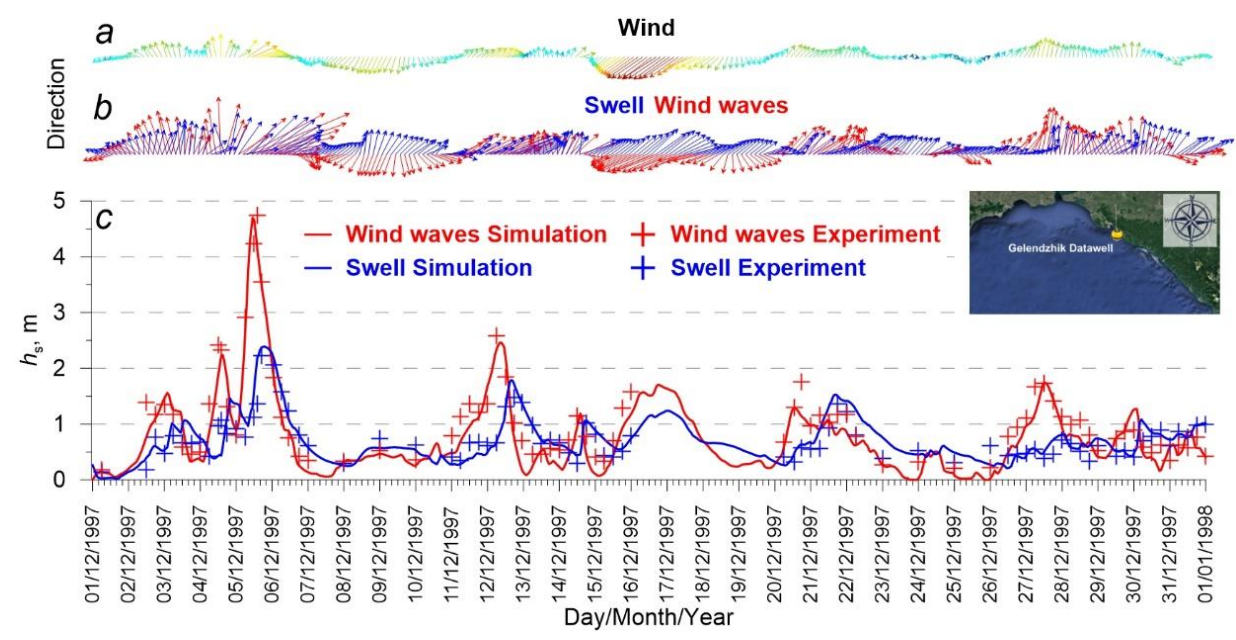

Fig. 1. Comparison of model and experimental parameters of the surface wave components for December 1997 at the point of Gelendzhik Datawell buoy station deployment: $a$-general wind direction; $b$ - the directions of swell wave (blue vector) and wind wave (red vector) propagation; $c$ - calculated and experimental significant heights of the wave components

Results. Based on the results of the research, the data array was obtained. It consists of fields of calculated parameters of the Black Sea wind-induced wave components with a time step of $1 \mathrm{~h}$ and covering a period of 38 years (1979-2016). A preliminary analysis of the wave climate features of the Crimean coastal zone was carried out for 5 characteristic points located in the western and southern parts of the considered region (Fig. 2). The local depth at each point is $30 \mathrm{~m}$. Repeatability along the directions of wind waves and swell is shown in Fig. 3 and 4.

The following features of the spatial distribution of the energy of surface waves are to be noted:

- at the entrance to the Karkinitsky Gulf (point 1 in Fig. 2), wind-induced waves of NE and SW rhumbs has the highest repeatability, swell - of WSW direction;

- on the sea boundary of the Kalamitsky Gulf (south-west coast, point 2), waves of different directions are observed, with the prevailing wind waves of NE, NW and SW directions, as well as swell of SW direction. Wind-induced wave of SW direction can reach a considerable power (100 and more $\mathrm{kW} / \mathrm{m})$; 
- at the southern extremity of the peninsula (point 3), two pronounced directions of wind waves - SE and NE - prevail. Swell occupies almost the entire southwestern sector;

- the southeastern coast between Ayu-Dag and Meganom Capes (point 4) is mainly prone to waves of ENE, E and SW directions, as well as swell of SW direction;

- in the area of the Feodosiya Gulf (point 5) wind-induced waves of NE and SW directions predominate. The most common swell is of SSE direction, the most powerful swell is of SSW direction.

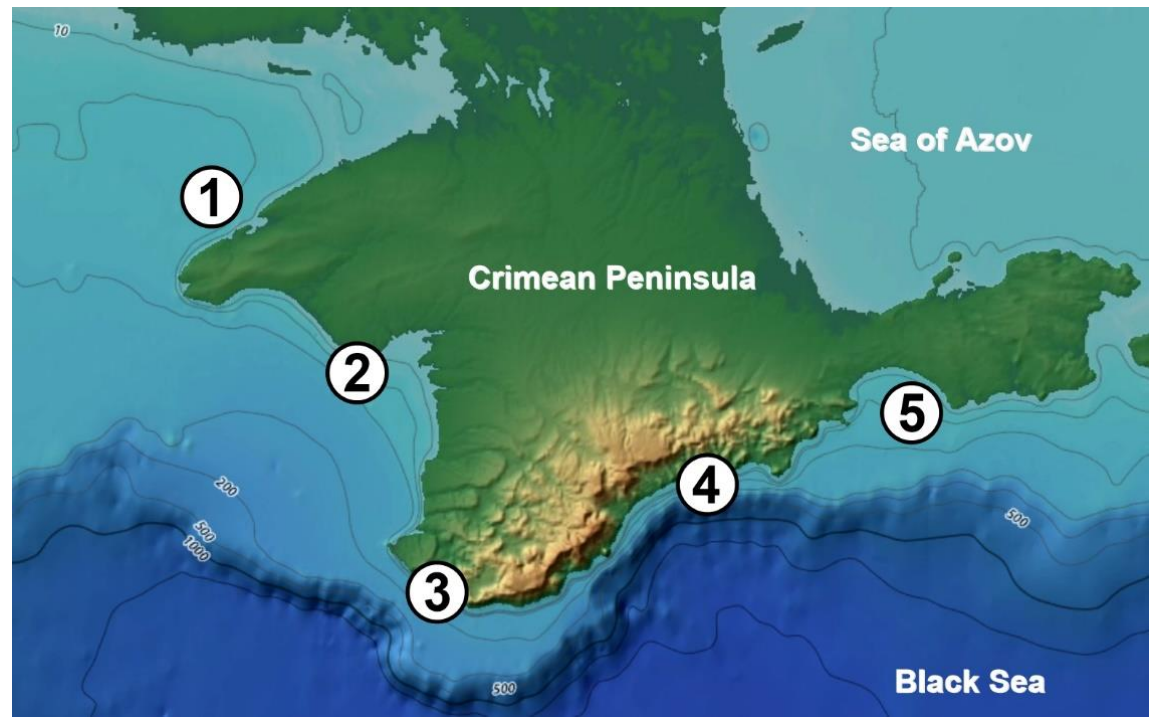

Fig. 2. Positions of characteristic points along the Crimean coast

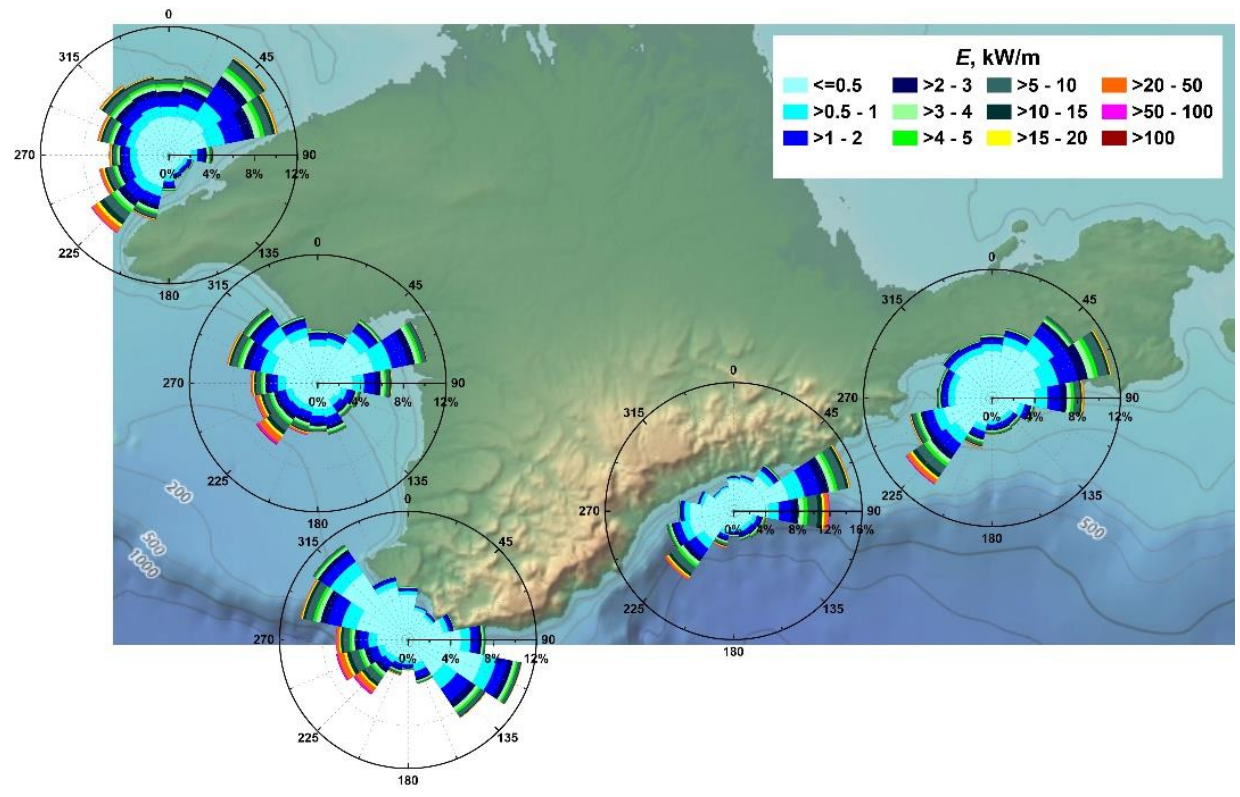

Fig. 3. Roses of wind-induced wave power $(\mathrm{kW} / \mathrm{m})$ for 5 characteristic points for 1979-2016 period 


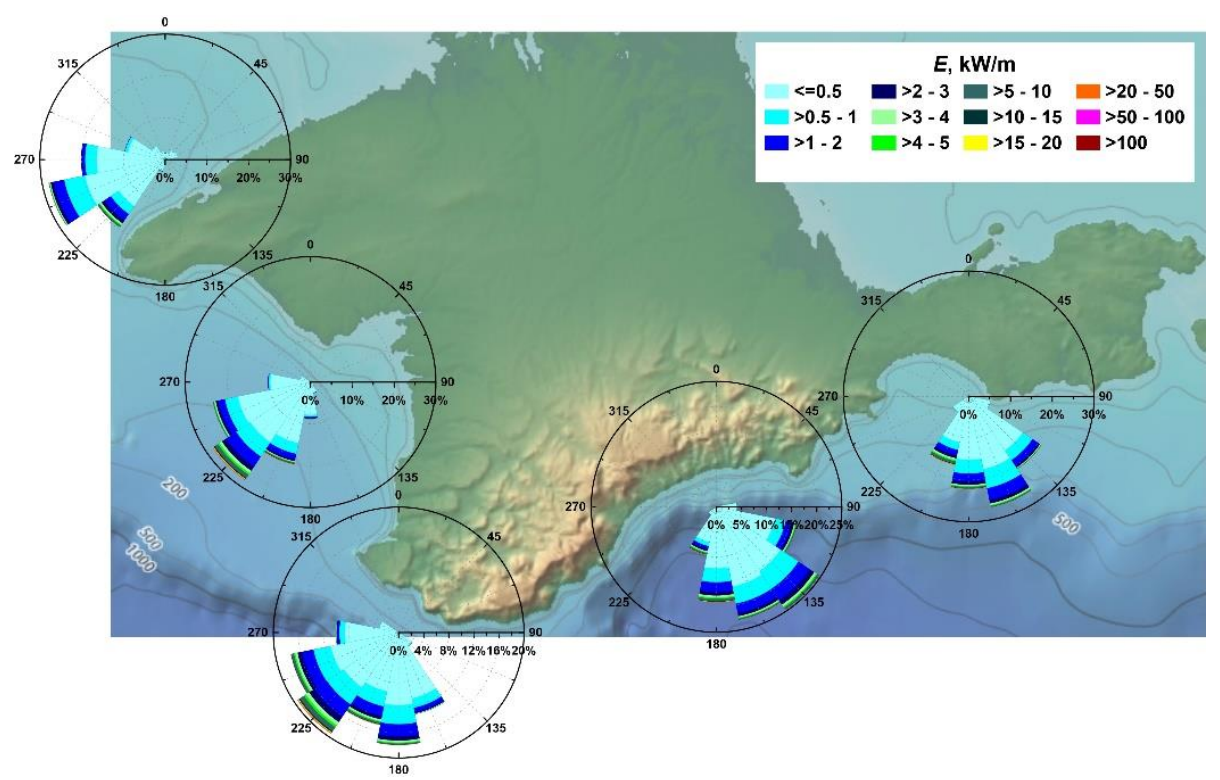

Fig. 4. Roses of swell wave power (kW/m) for 5 characteristic points for 1979-2016 period

The table gives estimates of some statistical characteristics of the main parameters of wind-induced waves and swell: significant wave heights $\left(h_{\mathrm{s}}\right)$, spectrum peak periods $\left(t_{\mathrm{p}}\right)$, average periods $\left(t_{\mathrm{z}}\right)$ and wave power $(E)$.

Statistical Characteristics of Wind-Induced Wave and Swell Wave Parameters (the maximum value $X_{\max }$, mean $X_{\text {mean }}$ and standard deviation $\sigma_{X}$ )

\begin{tabular}{c|c|c|c|r|r|r|r|r|r}
\hline \multirow{2}{*}{$\begin{array}{c}\text { Point } \\
\text { number }\end{array}$} & \multirow{2}{*}{ Parameter } & \multicolumn{2}{|c|}{$h_{\mathrm{s}}, \mathrm{m}$} & \multicolumn{2}{c|}{$t_{\mathrm{p}}, \mathrm{s}$} & \multicolumn{3}{c|}{$t_{\mathrm{z}, \mathrm{s}}$} & \multicolumn{2}{c}{$E, \mathrm{~kW} / \mathrm{m}$} \\
\cline { 3 - 9 } & & $\mathrm{WW}$ & $\mathrm{SW}$ & $\mathrm{WW}$ & $\mathrm{SW}$ & $\mathrm{WW}$ & $\mathrm{SW}$ & $\mathrm{WW}$ & $\mathrm{SW}$ \\
\hline 1 & $X_{\max }$ & 6.61 & 2.50 & 11.3 & 12.2 & 7.4 & 8.9 & 197.4 & 32.1 \\
& $X_{\operatorname{mean}}$ & 0.76 & 0.35 & 3.7 & 4.6 & 2.9 & 3.2 & 2.5 & 0.4 \\
& $\sigma_{X}$ & 0.65 & 0.20 & 1.2 & 1.4 & 0.8 & 0.7 & 6.1 & 0.8 \\
2 & $X_{\max }$ & 7.66 & 4.71 & 11.8 & 14.7 & 9.0 & 10.6 & 317.8 & 134.2 \\
& $X_{\operatorname{mean}}$ & 0.68 & 0.39 & 3.6 & 4.6 & 2.7 & 3.4 & 2.3 & 0.7 \\
& $\sigma_{X}$ & 0.63 & 0.29 & 1.3 & 1.5 & 0.8 & 0.9 & 8.1 & 2.4 \\
3 & $X_{\max }$ & 7.36 & 4.90 & 12.5 & 15.5 & 9.4 & 10.3 & 358.2 & 148.7 \\
& $X_{\operatorname{mean}}$ & 0.59 & 0.44 & 3.4 & 4.8 & 2.6 & 3.5 & 2.1 & 0.8 \\
& $\sigma_{X}$ & 0.62 & 0.29 & 1.4 & 1.5 & 0.9 & 0.8 & 8.1 & 2.2 \\
4 & $X_{\max }$ & 6.84 & 4.14 & 12.0 & 15.4 & 8.0 & 9.8 & 220.5 & 96.8 \\
& $X_{\operatorname{mean}}$ & 0.58 & 0.42 & 3.4 & 4.8 & 2.5 & 3.5 & 1.8 & 0.7 \\
& $\sigma_{X}$ & 0.59 & 0.29 & 1.3 & 1.6 & 0.8 & 0.8 & 5.5 & 1.8 \\
5 & $X_{\max }$ & 6.61 & 4.02 & 12.6 & 15.5 & 8.2 & 9.7 & 222.1 & 96.8 \\
& $X_{\operatorname{mean}}$ & 0.59 & 0.40 & 3.3 & 4.6 & 2.5 & 3.5 & 1.5 & 0.7 \\
& $\sigma_{X}$ & 0.55 & 0.27 & 1.1 & 1.5 & 0.7 & 0.8 & 4.8 & 1.7 \\
\hline
\end{tabular}

The main feature of the spatial distribution of wave energy along the Crimean coast should be noted: the contribution of swell waves to the total wave energy of surface waves significantly increases in the direction from the west coast to the east. If at point 1 the average significant height of pure wind waves is twice higher than the average height of swell waves, then at point 3 these heights are practically 
comparable. The most destructive storms are also observed at point 3 (southern extremity of the peninsula), where wind wave energy can exceed $350 \mathrm{~kW} / \mathrm{m}$.

Conclusions. Thus, the analysis of mixed surface waves with the automatic separation of the components of wind-induced waves and swell, as well as climatic features of the distribution of wind waves and swell in the Crimean coastal area.

Main results of the work carried out:

- optimal setups of the spectral wave model for automatic separation of wave components are determined;

- a database of wind-induced waves and swell parameters in the Black Sea water area for 1979-2016 was obtained;

- in the coastal area of the Crimean Peninsula, the greatest frequency is surface waves with significant wave heights up to $1 \mathrm{~m}$;

- the distribution of the periods is of a two-peak nature, the peaks corresponding to two wave systems - purely wind-induced waves (3.0-3.5 s) and swell $(\sim 4 \mathrm{~s})$;

- the contribution of swell waves to the total wave energy of surface waves increases in the direction from the west coast to the east. On the west coast, the proportion of swell (in the average annual balance) is $\sim 15 \%$, in the southeast one this contribution already exceeds $30 \%$.

In the future, the materials obtained will be used in simulation of lithodynamic processes in the coastal zone of Crimea, as well as in the analysis of extreme wave events.

\section{REFERENCES}

1. Resio, D., Bratos, S. and Thompson, E., 2002. Meteorology and Wave Climate. In: Coastal Engineering Manual. Part II: Hydrodynamics. Chapter II-2: Engineer Manual 1110-2-1100. Washington, DC: U.S. Army Corps of Engineers, 72 p. Available at: http://coastalengineeringmanual.tpub.com/Part-II-Chap2/ [Accessed 10 November 2017].

2. Dee, D., Uppala, S., Simmons, A., Berrisford, P., Poli, P., Kobayashi, S., Andrae, U., Balmaseda, M.A., Balsamo, G. [et al.], 2011. The ERA-Interim Reanalysis: Configuration and Performance of the Data Assimilation System. Q.J.R. Meteorol. Soc., 137(656), pp. 553-597. doi:10.1002/qj.828

3. Semedo, A., Sušelj, K., Rutgersson, A. and Sterl, A., 2011. A Global View on the Wind Sea and Swell Climate and Variability from ERA-40. Journal of Climate, [e-journal] 24(5), pp. 1461-1479. doi:10.1175/2010JCLI3718.1

4. Zheng, K., Sun, J., Guan, C. and Shao, W., 2016. Analysis of the Global Swell and Wind Sea Energy Distribution Using WAVEWATCH III. Advances in Meteorology, 2016, Article ID 8419580, p. 9. doi:10.1155/2016/8419580

5. Portilla, J., Caicedo, A., Padilla-Hernández, R. and Cavaleri, L., 2015. Spectral Wave Conditions in the Colombian Pacific Ocean. Ocean Modelling, 92, pp. 149-168. doi:10.1016/j.ocemod.2015.06.005

6. Zheng, C.W. and Li., C.Y., 2017. Analysis of Temporal and Spatial Characteristics of Waves in the Indian Ocean Based on ERA-40 Wave Reanalysis. Applied Ocean Research, 63, pp. 217-228. doi:10.1016/j.apor.2017.01.014

7. Boukhanovsky, A.V. and Lopatoukhin, L.I., 2015. Statistica Shtormov na Morskikh Akvatoriyakh (Alternativniy Podkhod) [Storms Statistics at Sea (Alternative Approach)]. Fundamentalnaya i Prikladnaya Gidrofizika = Fundamental and Applied Hydrophysics, 8(4), pp. 86-91 (in Russian). 
8. Kos'yan, R.D., Divinsky, B.V. and Pushkarev, O.V., 1998. Measurements of Parameters of Wave Processes in the Open Sea near Gelendzhik. In: The Eight Workshop of NATO TUWAVES/Black Sea. Ankara, Turkey: METU, pp. 5-6.

9. Berkün, U., 2007. Wind and Swell Wave Climate for the Southern Part of Black Sea: Thesis. Ankara, Turkey: Graduate School of Natural and Applied Sciences of METU, 141 p. Available at: https://etd.lib.metu.edu.tr/upload/12608139/index.pdf [Accessed 10 October 2017].

10. Van Vledder, G.P. and Akpnar, A., 2016. Spectral Partitioning and Swells in the Black Sea. In: ICCE, 2016. Proceedings of the $35^{\text {th }}$ International Conference on Coastal Engineering: Antalya, Turkey, 17-20 November. Vol. 35, pp. 199-212. Available at: https://repository.tudelft.nl/islandora/object/uuid:5c966d7f-de6a-4346-8658-14ec90e9728e [Accessed 10 October 2017].

11. DHI, 2017. MIKE 21, Spectral Wave Module. Scientific Documentation. Hørsholm: DHI headquarters. Available at: http://manuals.mikepoweredbydhi.help/2017/Coast_and_Sea/M21SW_Scientific_Doc.pdf [Accessed 10 October 2017].

12. Divinsky, B.V. and Kosyan, R.D., 2017. Spatiotemporal Variability of the Black Sea Wave Climate in the Last 37 Years. Continental Shelf Research, 136, pp. 1-19. doi:10.1016/j.csr.2017.01.008

13. Siadatmousavi, S.M., Jose, F. and Stone, G.W., 2011. Evaluation of Two WAM White Capping Parameterizations Using Parallel Unstructured SWAN with Application to the Northern Gulf of Mexico, USA. Applied Ocean Research, 33(1), pp. 23-30. doi:10.1016/j.apor.2010.12.002

14. Christie, D., Vögler, A., Morrison, J., Greenwood, C., Venugopal, V. and Topper, M., 2014. The Hebridean Wave Model. In: Proc. of the 2nd International Conference on Environmental Interactions of Marine Renewable Energy Technologies (EIMR2014). 28 April - 02 May. Stornoway, Isle of Lewis, Outer Hebrides, Scotland. Available at: https://tethys.pnnl.gov/sites/default/files/attachments/EIMR2014_723_Christie.pdf [Accessed 10 October 2017].

15. Bidlot, J., 2001. ECMWF wave-model products. In: ECMWF, 2001. ECMWF Newsletter, No. 9. Berkshire: ECMWF, pp. 9-15. Available at:

https://www.ecmwf.int/sites/default/files/elibrary/2001/14633-newsletter-no91-summer2001.pdf [Accessed 10 October 2017].

\section{About the authors:}

Boris V. Divinsky - Leading Research Associate, Laboratory of Geology and Lithodynamics, Shirshov Institute of Oceanology, Russian Academy of Sciences (36, Nahimovskiy pr., Moscow, 117997, Russia), PhD (Geogr.), ORCID ID: 0000-0002-2452-1922, ResearcherID: C-7262-2014, divin@ocean.ru

Ruben D. Kosyan - Head of the Laboratory of Geology and Lithodynamics, Shirshov Institute of Oceanology, Russian Academy of Sciences (36, Nahimovskiy pr., Moscow, 117997, Russia), Dr.Sci. (Geogr.), Professor, ResearcherID: C-5154-2014, rkosyan@ hotmail.com

Contribution of the co-authors:

Boris V. Divinsky - selection and analysis of literature, analysis and generalization of the research results, analysis of data, data representation in the text

Ruben D. Kosyan - general scientific supervision of the research, statement of the research general problem, formulation of conclusions

All the authors have read and approved the final manuscript.

The authors declare that they have no conflict of interest. 